\title{
Vestibular papillomatosis: interest of dermoscopy
}

\section{Clinical Image}

A 17-year-old patient with no significant pathological antecedent, without any notion of unprotected sex, have consulted for vulvar lesions whose date of onset was imprecise, was diagnosed before as condyloma.

The examination had objectified: soft, filiform projections at the palpation with symmetrical arrangement of 1 to $2 \mathrm{~mm}$ along both sides of the vulvar vestibule (arrows on Figure 1). In dermoscopy, these projections were pink like the rest of the mucosa, regular, symmetrical and linear, juxtaposed and their respective bases remained separate white arrows, (Figure 2). Abundant and irregular linear vessels were observed in the transparent nuclei of the papillae (blue arrow, Figure 2). In front of this aspects, diagnosis of vulvar physiological papillomatosis was suspected and was confirmed by histology on vulvar biopsy, notably by the absence of stigma and HPV infection.

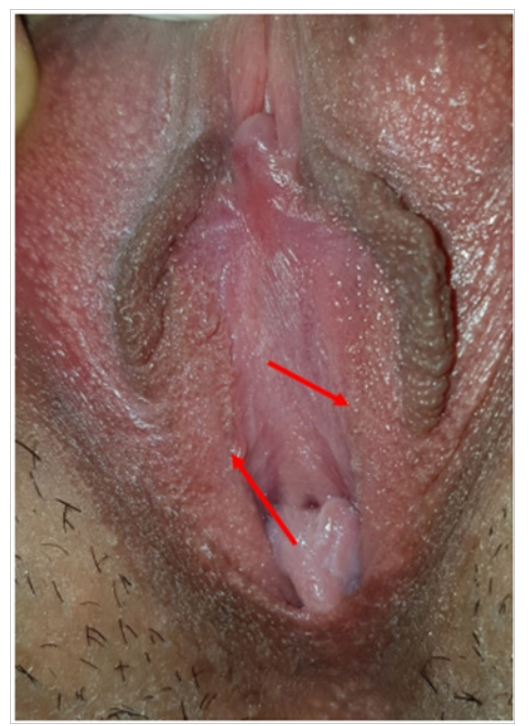

Figure I clinical image showing: soft, filiform projections with symmetrical arrangement along both sides of the vulvar vestibule (arrows).

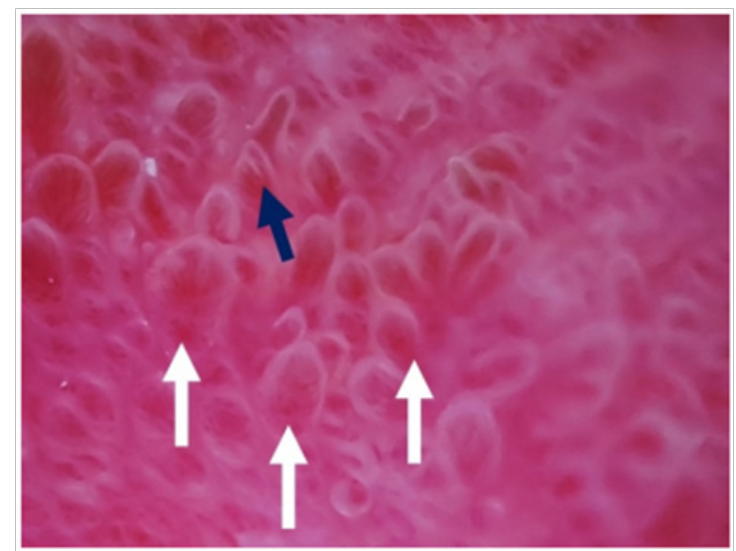

Figure 2 dermoscopycal image showing pink, regular, symmetrical and linear projections, juxtaposed with separate bases (white arrows) .Abundant and irregular linear vessels in the transparent nuclei of the papillae (blue arrow).
Volume 3 Issue 5 - 2019

\author{
Mounia Bennani, Rhizlane Chaoui , Hanane \\ Baybay, Sara Elloudi, Fatima Zahra Mernissi \\ Departememt of dermatology, Hassan II hospital university, \\ Morocco
}

Correspondence: Mounia Bennani, Dermatology-Venerology Department CHU hassan II FES, Morocco, Email mouniaabennani24@gmail.com

Received: June 12, 2019 | Published: September 09, 2019

The vestibular papillae represents an anatomical variant of the normal genital epithelium and is probably the female equivalent of pearly penile papules. It is thought that they are present in $1 \%$ of women, and this low percentage may be due to their lack of knowledge by practitioners since their diagnosis are often wrongly spotted as condyloma acuminates hence the role of dermoscopy, which objectives in case of condyloma multiple irregular projections with tapered ends, whiter and wider than the vestibular papillae, with hemorrhages (small red or black dots or striae), glomerular vessels or may also be also present in point (Figure 3) we then allow to avoid aggressive investigations, heavy therapies and anxiety in patients.

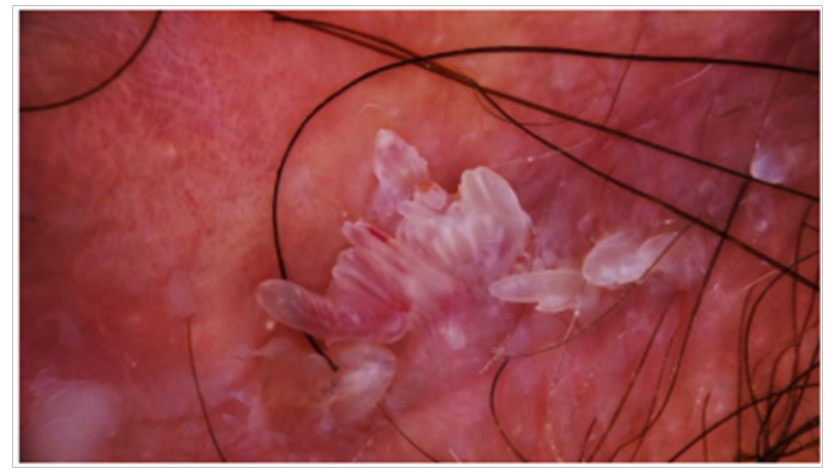

Figure 3 dermoscopycal image of a vulvar condyloma acuminate showing multiple irregular projections with tapered ends, whiter and wider than the vestibular papillae.

\section{Acknowledgments}

None.

\section{Funding}

None.

\section{Conflicts of interest}

Author declares that there is no conflict of interest. 